\title{
REITER'S DISEASE*'
}

\author{
BY
}

\author{
A. H. HARKNESS \\ Joint-Director Endell Street Clinic, St. Péter's and St. Paul's Hospital (Institute of Urology); \\ Consultant in. Venereal Diseases to St. Charles' Hospital; \\ the Civil Consultant in Venereal Diseases to the Royal Navy
}

Reiter's disease is characterized by a clinical syndrome consisting of a primary abacterial urethritis of venereal origin, bilateral conjunctivitis, polyarthritis; frequently balanitis, and sometimes keratodermia blennorrhagica; cardiac and other manifestations have also been described.: The ætiology is unknown.

There is an almost identical syndrome associated with the various types of dysentery (the primary focus of infection in these cases is the bowel and not the urethra) which is probably the same disease. There are also certain other diseases and reactions due to treatment which may simulate the syndrome very closely.

In my experience true Reiter's disease is one in which the primary focus of infection is an abacterial urethritis of venereal origin with blood-borne complications. (In none of my cases have I observed dysenteric symptoms nor have any of them shown a previous history of dysentery.) The syndrome may be complete or incomplete. It is commonly pyrexial, sometimes runs a protracted course, and often recurs after short or long periods of remission. In my series two separate attacks occurred in twenty-four patients, three in four, and four in one : the syndrome was never complete in more than one attack.

It has frequently been reported to me by my male. nurses at St. Charles's Hospital that patients with the syndrome, including those acutely ill, invariably have voracious appetites.

From the many references to Reiter's disease which have appeared. recently in the literature, it seems that several misconceptions exist on the subject. Much of the confusion would appear to be due to the fact that the disease bears Reiter's name. In his case, reported in 1916, the illness was ushered in with severe abdominal pain, diarrhœa and blood-stained stools, followed eight days later by a purulent urethral discharge with bilateral conjunctivitis. On the ninth day there was an acute polyarthritis, and six weeks later numerous pustules were noted in the region of the left hip

\footnotetext{
*An Address to the Medical Society for the Study of Venereal Diseases, April 29. 1949.
}

joint. This appears to me to have been a clear case of the dysenteric syndrome. Description of the syndrome, until the ætiology is established, would be facilitated if a distinct differentiation were made between cases of venereal and those of dysenteric origin. I advocated in 1947 that the term " Reiter's disease," or better still " dysenteric arthritis," be applied only to the latter, and that the former-those of venereal origin-be described as "non-gonococcal polyarthritis" or " the nongonococcal syndrome." Much confusion would, I am convinced, be avoided by such a distinction.

The venereal syndrome, as we know it today, was recognized many years before Reiter published his case, indeed a case in which the syndrome was complete was described by Launois in 1899 . In this instance there had been five previous attacks of gonorrhœa, the syndrome developing during an attack of urethritis in which gonococci could not be found in the discharge or urine, the latter being heavily infected with Bacillus coli.

Priority in the description of the syndrome urethritis, conjunctivitis, and arthritis, however, should be accorded to Sir Benjamin Brodie, who in 1818 gave a full description of one typical case and referred in some detail to four others. $\dagger$

Two of the original forty-four cases of abacterial urethritis of venereal origin described by Wælsch in 1916 developed blood-borne complications, one rheumatic pains in both knees and ankles, and the other bilateral conjunctivitis two days- after the urethral discharge was noticed. Inflammation of the eyes reappeared four months later following intercourse with the same woman. Wælsch (1916) considered that the eyes were infected by fingers contaminated with the urethral secretion.

In dealing with this subject it is difficult to know how many of the clinical entities of the syndrome are necessary before it is possible to make a diagnosis of Reiter's disease. Should only the cases in which the syndrome is complete be reviewed, or should the primary focus of infection, together with one, two, or three of the blood-borne

† This was brought to my notice by my friend Robert Milne. 
TABLE I

\begin{tabular}{|c|c|c|c|c|c|c|c|}
\hline 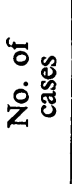 & 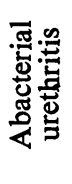 & ర) & & 总 & 苞 & 总苟 & 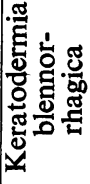 \\
\hline 6 & + & . & - & - & - & - & - \\
\hline 40 & + & - & - & + & - & - & - \\
\hline 2 & + & - & + & - & - & - & - \\
\hline 2 & + & + & + & - & - & - & - \\
\hline 18 & + & + & - & + & - & - & - \\
\hline 25 & + & + & - & + & - & - & + \\
\hline 8 & + & - & - & + & - & - & + \\
\hline 2 & + & $\overline{-}$ & $\bar{z}$ & $\bar{z}$ & $\overline{1}$ & \pm & - \\
\hline & + & - & - & - & + & - & - \\
\hline
\end{tabular}

complications warrant their inclusion in the description? Conjunctivitis is commonly mild and ephemeral ; the balanitis and keratodermia blennorrhagica (unless generalized) are often inconspicuous and symptomless; the three conditions are therefore easily overlooked as they have been in many cases of polyarthritis referred to me for treatment. On the other hand the arthritic manifestation of the disease is invariably disabling and was present in all the cases described in the literature except the third case of Stühmer's series, Roth's case, and thirteen of mine which are described below.

Many of the doubtful cases described in the literature, including that of Lojander (1927), in which there was no evidence of infection in the urinary tract, are commonly associated with atypical skin lesions, usually hyperkeratotic rupial patches and not nodules. However, in one of my cases, in which there were three attacks, the syndrome was complete during the first illness and in the third a unilateral iritis and polyarthritis occurred with no signs or symptoms in the urinary tract.

In my description of the venereal syndrome I shall include all cases of primary abacterial urethritis together with one or more of the blood-borne

TABLE II

PRIMARY MIXED INFECTIONS (GONOCOCCAL AND NONGONOCOCCAL)

\begin{tabular}{c|c|c|c|c}
\hline $\begin{array}{c}\text { No. } \\
\text { of } \\
\text { cases }\end{array}$ & $\begin{array}{c}\text { Abacterial } \\
\text { and } \\
\text { gonococcal } \\
\text { urethritis }\end{array}$ & $\begin{array}{c}\text { Ocular } \\
\text { mani- } \\
\text { festations }\end{array}$ & Arthritis & $\begin{array}{c}\text { Kerato- } \\
\text { dermia } \\
\text { blennor- } \\
\text { rhagica }\end{array}$ \\
\hline 7 & + & - & + & - \\
3 & + & + & + & - \\
1 & + & + & + & + \\
1 & + & + & + & + \\
\hline
\end{tabular}

No cases from the pre-penicillin era are included. Blood-borne complications occurred one to twenty-six days after successful penicillin therapy for the gonococcal element in the urethral discharge. complications of bilateral conjunctivitis, arthritis, and keratodermia blennorrhagica. Details of this series are given in Table I. I shall also include twelve cases in which the gonococcus was present in the urethral discharge before the commencement of treatment for urethritis (Table II). It is presumed that penicillin destroyed the gonococcal element in the urethral discharge and that the residual abacterial infection caused the subsequent development of blood-borne complications.

All the patients included in Tables I and II were males. The disease is extremely rare in females ; indeed there are many workers who maintain that it never occurs in women. In 1945 I was able to find only nine cases of keratodermia blennorrhagica recorded in women (Harkness, 1945). I have had two cases in which a non-gonococcal cervical discharge (cultures for " $L$ " organisms being positive in both) was associated with polyarthritis and typical lesions of keratodermia blennorrhagica (one also suffered from bilateral conjunctivitis); and I saw recently a similar case with Harman. I have had other cases of polyarthritis in women with a non-gonococcal cervicitis in which " $L$ " organisms have been cultured, but the absence of skin lesions made the diagnosis extremely difficult. As will be seen later, a number of cases have been reported in women in association with the dysenteric syndrome.

\section{Sequence of Syndrome}

In my series of cases in which it was possible to observe the progression of the disease, conjunctivitis was noted one to eighteen days (commonly six) after the appearance of the urethral discharge, and arthritis one to six days later. In two cases arthralgic pains in several joints were noted before the onset of conjunctivitis. Definite articular involvement did not occur until a few days later. Bilateral conjunctivitis associated with arthralgic pains and myositis with no subsequent development of arthritis was observed in two cases : conjunctivitis was not noted in two other cases associated with arthralgia only.

It must be emphasized, however, that in many cases, including some in which the syndrome has progressed to include keratodermia blennorrhagica, conjunctivitis has been either absent or so mild that it has been overlooked. This may be the explanation for the two cases with unilateral iritis which were not observed until two weeks after the onset of arthritis.

Balanitis is commonly noted soon after the onset of arthritis and always before the appearance of the rash. Early lesions of keratodermia blennorrhagica were noted in one case on the same day as 
the arthritis, but in all other cases it was not observed until at least a month after the onset of the disease.

\section{Urethritis and other Manifestations in the Urinary Tract}

The primary focus of infection, in the majority of cases, is a non-gonococcal abacterial urethritis. This is commonly ushered in with signs and symptoms of subacute (rarely acute) inflammation, though occasionally the urethra is the seat of primary mixed infections of both gonorrhoa and abacterial urethritis. In the latter, penicillin therapy eliminates the gonococcal element of the urethral discharge but the non-gonococcal element persists. In such circumstances acute arthritis, with or without the development of other blood-borne complications, may follow days or weeks later. In none of these cases have I been able to demonstrate gonococci in the residual urethral discharge, vesiculo-prostatic secretions, synovial fluid, or early lesions of keratodermia blennorrhagica, and for this reason I regard the complications as being of non-gonococcal causation (see Table II). It is reasonable to assume that there may also be primary mixed infections with an abacterial component and organisms other than gonococci, but uncertainty prevails owing to the lack of specific therapy for the elimination of the bacterial element. In view of this I have excluded from my series a few cases in which urethritis was considered to be bacterial (non-gonococcal).

Mild Onset of Inflammation shows itself as a subacute abacterial or Wælsch urethritis. This is characterized by a long incubation period (five to thirty days), mildness of symptoms, a clear, tenacious urethral discharge (this is occasionally muco-purulent, rarely purulent), and, in 60 per cent. of cases, a typical urethroscopic picture : this, in the early stages, shows wedge-shaped excrescences that appear to lie superficial to the mucous membrane of the anterior urethra with no obvious involvement of the subepithelial connective tissue. They are seen chiefly on the roof and lateral walls of the urethra, the base of each being attached to the mucous membrane with the pointed or blunted, acute-angled edge lying free and protruding into the urethral lumen. Later the excrescences become flatter and resemble cobble-stones that have been likened to the nodules of trachoma. It must be emphasized that this urethroscopic picture is present in a large percentage of cases with blood-borne complications.

"Urethroscopic" stricture, in which the lumen of the urethra is not diminished in calibre and presents no obstruction to the passing of a large instrument, is frequently observed in this type of urethritis, whereas "organic" stricture requiring dilatation treatment, observed in seven cases, was probably due to previous gonococcal inflammation.

Acute Onset of Urethritis is distinguished by a profuse muco-purulent or purulent urethral discharge simulating gonorrhœa, and severe pain on micturition which may precede the onset of urethral discharge; urethroscopy shows a generalized red and inflamed mucous membrane with no excrescences or infiltrations. In view of the acute symptoms cystoscopy has been carried out in only two of my cases before the commencement of treatment : on both occasions it revealed acute generalized cystitis. The cystoscopic picture is similar to that of abacterial pyuria and this is, in all probability, the same disease (Harkness and Henderson-Begg, 1948), the acute generalized cystitis being a local complication of a primary urethritis the infective agent of which may become blood-borne to cause Reiter's disease.

I have treated five cases of primary abacterial urethritis, four subacute and one acute, in which I have seen the complete syndrome of Reiter's disease subsequently develop.

In cases with subacute onset the urine is clear with threads in the first glass and clear in the second; though investigations will commonly reveal a symptomless prostatitis. In those in which the onset is acute there is obvious involvement of the posterior urethra; it is in this type of urethritis that hæmaturia is sometimes observed.

The urethral discharge in eight of my cases (one with the complete syndrome). was hæmorrhagic, and the urine contained blood. Upper urinary tract investigations during convalescence revealed dilated renal pelves in most cases. Colby (1944) describes three cases of Reiter's disease, the first with hæmaturia and prostatic abscess, the second with hæmaturia, right hydronephrosis, and prostatic abscess (which developed after nephrectomy), and the third with hæmaturia and dilatation of both renal pelves and ureters. Miller and McIntyre (1945) also reported two cases with hæmaturia associated with lesions of upper urinary tract, one with pyelitis and the other with dilated left renal pelvis.

\section{Conjunctivitis and Ocular Manifestations}

Inflammation of the conjunctiva commonly involves both eyes and, though in many the inflammation is more marked in one eye, $I$ have seen it unilateral in two cases only. It is usually associated with episcleritis and in most cases, as already mentioned, is mild. '(It may occasionally 
be severe, and was so in fourteen of my cases : in six of them it was the only blood-borne complication.)

Recurrent attacks (often in conjunction with rise of temperature, acute exacerbations of pain, and swelling in joints) are to be observed in cases resistant to treatment, and I have seen as many as three attacks during a three months' illness. Unilateral or bilateral iritis occurred in eight of my series, but in the first illness it was preceded by conjunctivitis in all but two. Unilateral iritis, during subsequent relapses of the disease, may be the only ocular lesion.

Herpes of the conjunctiva and cornea has been reported also, but some of these lesions may have been ocular manifestations of keratodermia blennorrhagica since vesicles, subsequently developing into erosions, appeared concomitantly with crops of typical lesions in other parts of the body.

\section{Arthritis}

Arthritis, the most constant blood-borne complicàtion, was absent in 13 (11 per cent.) of my 126 cases. In six the urethritis was associated with conjunctivitis; in two with conjunctivitis and arthralgic pains ; in two with arthralgic pains only ; in two with tenosynovitis involving the extensor tendons of the wrist; in one with inflammation of the right sub-deltoid bursa. Arthritis was also absent from the syndrome in the third case of Stühmer's series in which an acute non-gonococcal urethritis was associated with high fever and bilateral conjunctivitis. It was also absent in Roth's case that showed tenosynovitis of the extensor tendons of the right great toe and keratodermia blennorrhagica.

In all but twenty-one of my cases the onset of arthritis was acute, making it impossible to distinguish them from those in which a gonococcal ætiology was presumed to be certain. The cases in which it was subacute occurred more frequently in recurrent attacks of the disease. This complication is commonly polyarthritic. It was monarthritic on seven occasions only, but in these arthralgic pains with no swelling or limitation of movement were observed in other joints. Further joints became involved during treatment in 8 per cent. of the cases : in recurrent attacks the same joints were frequently involved. Previous joint injury or disease, predisposing to localization of infection, was rarely observed.

The order of frequency of the joints involved, including periostitis of the os calcis, was :

$\begin{array}{lllllc}\text { Joint } & & & & & \% \\ \text { Knee .. } & \ldots & \ldots & \ldots & \ldots & 70 \cdot 3 \\ \text { Ankle } & \quad . & . . & \ldots & \ldots & 55 \cdot 4\end{array}$

\begin{tabular}{|c|c|c|}
\hline Small joints & of feet & \\
\hline Small joints & or han & ads \\
\hline Wrist .. & $\ddot{. .}$ & $\cdots$ \\
\hline Periostitis & .. & $\cdots$ \\
\hline Sacro-iliac & .. & . \\
\hline Shoulder & .. & .. \\
\hline Elbow & .. & . \\
\hline Sterno-clavi & cular & . \\
\hline Acromio-cla & vicular & \\
\hline Intervertebr & & \\
\hline Hip & $\ldots$ & \\
\hline
\end{tabular}

As in blood-borne infections due to gonorrhœa, acute local complications such as epididymitis, acute prostatitis, etc., were not observed in any of the cases.

Radiographs of joints during the first month of the disease usually show an increase in joint space only, but when they are carried out later they often reveal diffuse or localized areas of osteoporosis, especially in the region of the articular ends of the small joints of the hands and feet. Spindle-shaped swellings, sometimes large, in the region of the interphalangeal and metacarpo-phalangeal joints are commonly due to inflammatory changes in the soft tissues: it is exceptional in such cases for radiographs to show any abnormality. However, I have observed bony changes, sometimes late in the first illness but more often during recurrent attacks.

In one patient generalized arthritic changes were seen in both hands. The proximal interphalangeal joint of the middle finger of the right hand also showed gross changes with loss of joint space, and there was periostitis of the first and second phalanges.

In another patient there was laxity of the ligaments of the right knee, allowing mild subluxation backwards with the knee in the flexed position, and with relaxed muscles. The metacarpo-phalangeal joint of middle finger of left hand showed the same, but more severe, laxity of ligaments. There was destruction of the anterior part of the head of the third metacarpal bone with osteoporosis of the head and the base of the adjacent phalanx ; also periostitis of the shaft of two bones on either side of the joint, and forward subluxation of the phalanx on the metacarpal.

I have previously reported a case (Harkness, 1945) in which there was marked laxity of the ligaments of the affected joints, especially the right knee, in which there was subluxation backwards of the right tibia, and also displacement outwards and internal rotation.

Radiographs of the knees of another patient (with a fifteen-year history of recurrent attacks of arthritis associated with conjunctivitis or iritis and urethritis) showed very irregular contours- of femoral and tibial condyles : the bone showed irregular sclerosis beneath the articular cortex. The joint space was narrowed (indicating erosion of cartilage) and there were large marginal osteophytes. There was almost complete 
fibrous ankylosis but radiographs showed no evidence of bony ankylosis. The case was one of osteo-arthritis supervening on destruction from acute inflammation.

In another case with a twelve-year history of recurrent attacks of non-gonococcal urethritis associated with arthritis there was extensive new bone formation in the soft tissues over the median femoral condyles and similar changes not so well marked over the external condyles.

I have seen six further cases, all occurring during the second, third, or fourth attack, in which osteo-arthritic changes were observed.

Periostitis of the os calcis with sub-calcanean spurs associated with plantar fasciitis was observed in fourteen cases. In one, spurs developed on both feet during an attack of gonococcal urethritis, conjunctivitis, and arthritis. They proved resistant to treatment and were excised with excellent results that showed immediately. However, a further attack of abacterial urethritis, polyarthritis with painful heels, and keratodermia blennorrhagica developed in the same patient five years later when a radiograph revealed that the two large spurs had reappeared.

In no cases did the infective process in joints progress to cause suppuration. As already mentioned, bursitis (the only metastatic complication on one occasion) was observed in five further cases associated with arthritis. Tenosynovitis in the two cases already referred to also occurred alone.

Bauer and Engleman (1942) in their investigations on the pathology of the joint changes, excised a small portion of synovial tissue (during the thirteenth week of the disease) from the left knee of a man aged 23 with the venereal syndrome. There were areas of suggested villous formation in the suprapatellar pouch (one of which was excised) with slight thickening and marked injection of the synovial membrane. Sections showed the synovial membrane to consist of several layers of cells with an excess of lymphocytes and plasma cells in the intercellular spaces : only an occasional leucocyte was seen. An œdematous subepithelial connective tissue was crammed full with a dense cellular infiltration with focal collections of lymphocytes and plasma cells forming a cuff surrounding the capillaries. Scrapings from the synovial membrane did not reveal the presence of inclusion bodies. On the other hand pathological investigations carried out by Wepler (1942) on a man with the dysenteric syndrome who died from intercurrent disease, showed œdema of the synovial membrane with complete absence of its cellular lining : the joint capsule and periarticular tissue were infiltrated with lymphocytes, but there were no changes in cartilage or bone.

\section{Balanitis}

Balanitis, usually called " balanitis circinata" in American literature, is seen frequently in association with arthritis, but it may occur before the onset of blood-borne complications. It is especially com- mon in uncircumcised subjects in which the prepuce completely covers the glans, and it was noted in 43 per cent.. of my cases. It consists of heaped up layers of scales which, when removed, leave a weeping surface due no doubt to exposure of the corium. Fresh scales soon appear, but to a lesser extent especially when the parts are cleansed with saline followed by the application of a bland powder.

In the first place there are multiple areas of inflammation, separated by normal mucous membrane. These soon coalesce to form one large serpiginous and sharply defined patch commonly situated either in the coronal sulcus or on the posterior two thirds of the glans, though occasionally the area involved surrounds the external meatus. The hard nodular lesions of keratodermia blennorrhagica may also appear on th? glans, usually in circumcised subjects, either alone or in association with soft patches.

\section{Keratodermia Blennorrhagica}

Keratodermia blennorrhagica occurred in thirtyfive of my series; in thirty-three in conjunction with primary abacterial urethritis and in two with prime mixed infection : it also occurred in three females. The development of vesicular, " pustular," and nodular lesions on the soles of the feet were observed in seven cases.

There are two types of lesion, the hard parakeratotic nodules with their three distinct phasesvesicle, pustule; and nodule-, and the soft, limpetlike parakeratotic patches consisting of many layers of scales, often heaped up centrally and resembling rupia, the former being more characteristic of the disease. Confusion in diagnosis commonly occurs when the latter appear unaccompanied by nodules, as is commonly the case in the dysenteric syndrome and arthropathic psoriasis. The nodules show a predilection for the soles of the feet, but there is occasionally a generalized distribution.

In a previous communication in May 1944 (Harkness, 1945), I submitted evidence that keratodermia blennorrhagica was a complication of non-gonococcal urethritis. I maintained that when it occurred in association with gonorrhœa there was a mixed infection of both diseases, though the gonococcal element played no part in the appearance of the eruption. Since then unlimited supplies of penicillin have become available, with the result that in mixed infections nowadays the gonococcal element is quickly eliminated, leaving behind it a residual non-gonococcal urethritis. Since my review of the cases in which gonococci were said to have been found in the skin lesions, Gately (1945) claims to have demonstrated Gram-negative diplo- . 
coccii on several occasions in his case, but cultures were omitted so that definite bacteriological proof is lacking. No organisms were found in a watery urethral discharge of four days' duration, the skin lesions on the hands and feet showed a marked inflammatory reaction and certainly were by no means typical of keratodermia blennorrhagica. The reader is referred to my previous communication (Harkness, 1945) for a more detailed description of this complication.

\section{Pyrexia}

As already mentioned, I have observed all stages of the development of the complete syndrome in five cases. The temperature in these was normal when a non-gonococcal discharge was the only manifestation of disease, but after the development of blood-borne complications the temperature in all registered $100^{\circ} \mathrm{F}$. or higher.

Pyrexia associated with the syndrome is extremely variable. Fifteen per cent. were apyrexial throughout the period of observation but they may have been pyrexial before admission under my care. Swinging temperatures which varied between $100^{\circ}$ and $103^{\circ} \mathrm{F}$. were recorded in 32 per cent. of the series (it was so in all cases with a genemolized eruption), all such patients being extremely ill and cachectic. An occasional slight rise in temperature was observed in the other cases.

\section{Cardiac Manifestations}

Two of my cases developed tachycardia with pulse rate which varied between 120 and 150 over periods of five to six weeks during the acute phase of the disease; however, the cardiologist could detect no cardiac lesions.

Lever and Crawford (1944) reported a cardiac lesion suggestive of a myocardial infarct in their first case in which a generalized rupioid eruption was associated with urethritis. Feiring (1946) reported the prolongation of the auricular-ventricular conduction in two cases. One of Warthin's cases (1948) had symptoms suggestive of acute myocarditis but, following treatment with streptomycin, the heart rhythm and sounds became normal.

\section{Erythrocyte Sedimentation Ràte}

The erythrocyte sedimentation rate, by the Westergren method using a $200-\mathrm{mm}$. tube, was carried out at weekly intervals on all my cases, a figure of $12 \mathrm{~mm}$. being regarded as the upper normal limit. In a large proportion of cases the test registered $100 \mathrm{~mm}$. or more, a rate of $135 \mathrm{~mm}$. being not uncommon, and the lowest recorded rate was $18 \mathrm{~mm}$. Generally speaking the highest rates occurred in the severest types of the syndrome.
The erythrocyte sedimentation changes were a poor guide to success or failure of treatment, this being possibly due to the relapsing nature of the disease.

Only slight insignificant falls after both fever therapy and myochrysine were noted in patients acutely ill, but in mild apyrexial forms of the disease a normal erythrocyte sedimentation rate was not uncommon after treatment. A fall was noted in cases receiving sodium salicylate gr. 30 six-hourly, in one from 67 to 26 , and in another from 22 to 6 . In the two cases treated with streptomycin there was a rise, one from $63 \mathrm{~mm}$. to $125 \mathrm{~mm}$. and the other from $104 \mathrm{~mm}$. to $121 \mathrm{~mm}$. Dienes and his collaborators (1948) also noted that the erythrocyte sedimentation rate remained high for considerable periods after streptomycin had been administered. In two cases of myositis associated with an abacterial urethritis the erythrocyte sedimentation rate was normal both before and after treatment.

\section{The Dysenteric Syndrome}

It has been known for many years that dysentery may be complicated by obstinate attacks of arthritis, indeed Manson-Bahr (1943) states that Cælius Aurelianus described the condition (rheumatismus intestinalis cum ulcere) at the beginning of the fifth century. Kraüter (1871) reported both arthritis and conjunctivitis in association with the disease, and Markwald (1904) the first case with urethritis, conjunctivitis, and arthritis three weeks after the commencement of an attack of Shiga dysentery. Singer (1915), in a series of six hundred cases of bacillary dysentery, observed several cases with myalgia and conjunctivitis, seven with arthritis, and only one with urethritis. Feissinger and Leroy (1916), in a study of an epidemic of bacillary dysentery on the Somme in 1916, noted, a few months before Reiter, the same clinical syndrome (syndrome conjunctivo-urétro-synovial) in four of their cases.

The majority of the cases develop the syndrome after apparent recovery from dysentery but, as in Reiter's case, it may also occur during the acute phase of the disease. Polyarthritis has been described in association with the various types of bacillary dysentery-more often Shiga and Flexner - and cases have also been reported by Moorhead (who noted six), by Feissinger and Leroy (1916), and by Manson-Bahr (1945), in which it appeared during or after an attack of amœbic dysentery. Gabrielle and others (1938) reported a case of nongonococcal urethritis and arthritis in a patient suffering from diarrhœa due to Giardia lamblia.

The frequency of arthritis in epidemics of bacillary dysentery varies considerably, as shown by the fact that in one epidemic (1897) in the Fiji Islands 
10 per cent. of the cases developed this complication, whereas in a further epidemic in the same colony thirteen years later (observed by Manson-Bahr (1920), there were none. The syndrome triad is in fact more frequently observed incomplete.

Gounelle and others (1940) described fifty cases of arthritis that occurred during a mild epidemic of Flexner dysentery, of which 46 per cent. were associated with urethritis and 68 per cent. with bilateral conjunctivitis. In Kokko's series (1945) due to the Flexner bacillus, 111 of 555 cases were suffering from conjunctivitis, and only three with purulent urethritis, but ninety more patients complained of pain on micturition : the syndrome triad was complete on three occasions only.

In Cimbal's (1942) series 82 per cent. were suffering from conjunctivitis and 47 per cent. from urethritis. In Paronen's series of 344 cases of Reiter's disease (310 males and 34 females) in which 71 per cent. developed during the acute phase of dysentery due to Flexner bacillus, the syndrome triad was complete in $233(69 \cdot 8$ per cent.). There were no cases in which urethritis was the only symptom, although it was the initial symptom in a slightly larger percentage of cases $(23.9$ per cent.) than arthritis (23.3 per cent.): arthritis occurred in $97 \cdot 3$ per cent.

Smyly states that the synovial fluid from cases of dysenteric arthritis occasionally shows the Bacillus dysenteria in both smears and cultures, but I know of no cases with the triad of symptoms in which this has been so. The blood serum in a small percentage of cases agglutinates the type of organism responsible for the enteritis, as in the cases reported by Markwald (1904), Beiglböck (1943), Cimbal (1942), Paronen (1948), and Gounelle and others (1940). Positive agglutination tests with the synovial fluid have also been reported, and, Smyly maintains, in a titre even higher than that of the blood serum, whereas Gounelle and his collaborators (they obtained strongly positive reactions in the blood serum up to $1 / 400$ in three

TABLE III

AGGLUTINATION TESTS WITH DYSENTERY ORGANISMS OF NORMAL SERA AND SERA FROM CASES OF URETHRITIS

\begin{tabular}{|c|c|c|c|c|c|c|c|c|}
\hline \multirow{3}{*}{ Case } & \multicolumn{8}{|c|}{ Antigen } \\
\hline & \multirow{2}{*}{ Shiga } & \multicolumn{2}{|c|}{ Flexner } & \multirow{2}{*}{103} & \multirow{2}{*}{119} & \multirow{2}{*}{ Newcastle } & \multirow{2}{*}{ Schmitz } & \multirow{2}{*}{ Sonne } \\
\hline & & $\bar{X}$ & $\mathbf{Y}$ & & & & & \\
\hline $\begin{array}{r}1 \\
2 \\
3 \\
4 \\
5 \\
6 \\
\\
7 \\
8 \\
9 \\
10 \\
11 \\
\\
12 \\
13 \\
\\
14 \\
15 \\
16 \\
17\end{array}$ & $\begin{array}{l}- \\
- \\
- \\
- \\
- \\
- \\
- \\
- \\
- \\
-\end{array}$ & 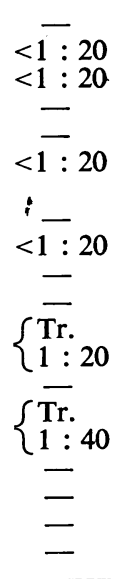 & 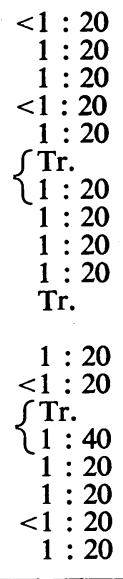 & $\begin{array}{c}- \\
\bar{Z} \\
<1: 20 \\
<1: 20 \\
- \\
- \\
- \\
- \\
- \\
- \\
- \\
-\end{array}$ & $\begin{array}{l}\overline{-} \\
<1: 20 \\
<\overline{1: 20} \\
<1: 20 \\
<\overline{1: 20} \\
\overline{-} \\
<1: 20 \\
- \\
<1: 20 \\
- \\
- \\
-\end{array}$ & $\begin{array}{l}- \\
- \\
- \\
= \\
- \\
- \\
- \\
- \\
- \\
-\end{array}$ & $\begin{array}{l}- \\
- \\
- \\
- \\
- \\
- \\
- \\
- \\
-\end{array}$ & $\begin{array}{l}- \\
- \\
- \\
z \\
z \\
- \\
- \\
- \\
- \\
-\end{array}$ \\
\hline $\begin{array}{l}\text { Normal } \\
\text { Controls }\end{array}$ & & . & & & & & & \\
\hline $\begin{array}{l}1 \\
2 \\
\\
3 \\
4\end{array}$ & $\begin{array}{l}- \\
- \\
-\end{array}$ & $\begin{array}{l}- \\
1: 20 \\
-\end{array}$ & $\begin{array}{l}\left\{\begin{array}{l}\text { Tr. } \\
1: 20\end{array}\right. \\
\left\{\begin{array}{l}\text { Tr. } \\
1: 40\end{array}\right. \\
<1: 20 \\
<1: 20\end{array}$ & $\begin{array}{l}- \\
- \\
-\end{array}$ & $\left\{\begin{array}{l}\overline{\mathrm{Tr}} \\
1: 20 \\
-\end{array}\right.$ & - & $\begin{array}{l}- \\
- \\
-\end{array}$ & - \\
\hline
\end{tabular}

$-=$ No agglutination in 10 minutes with thick suspension on slide. Tr. $1: 20=$ feebly $1: 20$.

There was no significant agglutination of organisms of the dysentery group. 
cases, $1 / 320$ in one case, slightly positive up to $1 / 50$ in one case, and negative in one case) considered that the results in the synovial fluid were similar to those-of the blood.

In Paronen's series agglutination tests on the blood serum were positive in 61 of 132 examined, in titres varying between 1 in 80 to 1 in 640 , and on the joint fluid in eight of the twenty-four examined.

Arthritic and ocular manifestations are similar in most respects to those already described in association with the venereal syndrome. A very detailed investigation of the bony changes was carried out by Gounelle and his collaborators : $\boldsymbol{x}$-ray examinations during the first month were always normal (as it was in all of Cimbal's cases) but two to three months later changes were often observed, especially in the extremities of the bones. Osteoporosis was the most frequent finding, but in some cases there were bony erosions causing indistinct bone margins, a condition which also occurs in association with the venereal syndrome and is described as a periosteal reaction. These workers also observed osteophytes in eight of their cases and, in view of this, consider that dysenteric arthritis should be renamed post-dysenteric osteoarthritis. Paetzel (1928) reported a case in which the radiograph of a toe showed atrophy of a joint with partial ankylosis.

Urethritis has been noted in only a small percentage of cases of dysenteric arthritis, and the urethroscopic picture has not been included in any of the descriptions. Involvement of the body of the testicle and epididymis occurred in nine of Paronen's series: six with pain and tenderness but no swelling, one with acute orchitis, and two with epididymo-orchitis.

Skin Eruptions in association with the dysenteric syndrome are extremely rare and-usually consist of the soft parakeratotic rupia-like patches seen occasionally in the venereal syndrome : it occurred only twice in Paronen's series of cases. Balanitis has also been noted by several workers, and in Paronen's series it occurred in 32.9 per cent. usually in association with urethritis. Epistaxis was reported by Gounelle and his collaborators in a large number of their cases and was considered to be due to an increase in the coagulation time of the blood.

Recurrences of arthritis are infrequent, and four of the ten described by Paronen were preceded by diarrhœa. However, this worker noted recurrence of urethritis in six, and of conjunctivitis in fifty cases during treatment for arthritis.

\section{Diagnosis}

As will be seen from the above descriptions, the venereal and dysenteric syndrome are, in all probability, the same disease and caused by the same infective agent, the portal of entry in the former being the urethra and in the latter the diseased mucous membrane of the large intestine.

In some cases reported in the literature, as in the one described by Thiers and Joly (1948), it is difficult to determine whether the syndrome is venereal or dysenteric. These authors state that only the third attack of urethritis, iritis, and arthritis was associated with dysenteric symptoms, but the blood did not agglutinate dysentery bacilli.

It must be noted, however, that the venereal syndrome has rarely been reported in women, whereas many such cases have occurred in association with the dysenteric syndrome. Indeed it was so in thirty-four of the 344 cases described by Paronen. One of Paronen's cases occurred in a boy aged two and a half years. Two further cases in boys aged 12 and 4 respectively were reported by Shiga (1904) and Florman and Goldstein (1948). No cases of the venereal syndrome have been reported in children. In the dysenteric syndrome, too, recurrences are infrequent and the skin manifestations are commonly parakeratotic patches and not nodules.

Before proceeding it is necessary to mention that quite a large number of workers consider, wrongly I think, that the syndrome has no connection with venereal disease. Indeed an annotation in the British Medical Journal of Dec. 7, 1946, states emphatically that the disease bears no relation to sexual intercourse.

The synovial fluid is the same in both syndromes. In my cases it was commonly straw-coloured and somewhat turbid and the cell exudate consisted of both polymorpho-nuclear leucocytes and lymphocytes, usually with a predominance of the former, but sometimes of the latter. No organisms (including $M$. tuberculosis) were seen in smears, and cultures were always sterile. Similar findings have been reported in the dysenteric syndrome. Smyly (1937) states that the Bacillus dysenteria has been cultivated in the synovial fluid but very few cases have been reported in the literature.

The fact that the blood serum and synovial fluid may agglutinate dysenteric bacilli does not necessarily indicate that the syndrome is due to dysentery : it may simply show that the patient has or has had dysentery. In the same way a positive gonococcal complement fixation reaction obtained in cases with primary mixed infections of both gonorrhœa and abacterial urethritis may only indicate that the patient has or has had gonorrhœa. 
Agglutination tests with dysenteric organisms were carried out for me by Bushby on blood sera of seventeen of my cases of venereal origin (six in which the syndrome was complete) and on four normal subjects. There were no significant agglutinations of organisms of the dysentery groups, the antigens used being Shiga, Flexner X, Y, 103, and 119, Newcastle, Schmitz, and Sonne.

The occurrence of arthritis, with or without other blood-borne complications soon after the elimination of gonococci from the urethral secretions, demands a thorough search for these organisms in the vesiculo-prostatic secretions and synovial fluid before a diagnosis of Reiter's disease can be made. It is essential that the aspiration of joints is carried out as soon as possible. So far I have failed to detect gonococci in such cases.

Difficulties in diagnosis due to primary mixed infections may also arise in countries in which lymphogranuloma inguinale is prevalent. Frei tests, carried out with either mouse brain antigen or lygranum on a large number of my cases, were negative in all.

Professor Bedson kindly carried out complement fixation tests for antibodies of the lymphogranuloma inguinale virus on the blood sera of twenty of my cases, nine in which the syndrome was complete and eleven incomplete. Complete fixation occurred in only one of the former group (at a dilution of 1 in 32) and in two of the latter (one at a dilution of 1 in 16, the other at 1 in 64): Frei tests were negative in all three cases. It is interesting to note that no antibodies were detected in the blood serum of a case of uncomplicated subacute abacterial urethritis in which indisputable virus inclusions were present in urethral scrapings.

Skin Sensitivity Tests.-Storm-Mathisen (1946) described a skin test for.Reiter's disease which employed a mixture of joint exudate and gland emulsion obtained from a case of this disease. A red papule $(12 \mathrm{~mm}$.), increasing slightly in size up to the eighth day and persisting for several months, developed forty-eight hours after intradermal inoculation in five cases diagnosed as suffering from Reiter's disease. A negative result followed the inoculation of eleven controls, including three with polyarthritis rheumatica.

I employed, for skin testing, a phenolized suspension of " $L$ " organisms prepared by HendersonBegg. Intradermal tests were, in the first place, carried out in normal subjects and it was determined that at a dilution of $1: 20$ this antigen gave rise to no more reaction in the normal skin than the control inoculation 0.5 per cent. phenol saline. In sensitized guinea-pigs the intradermal inoculation of $0.1 \mathrm{c.cm}$. of the diluted antigen resulted, after five to seven hours, in the development of a wide area of erythema with marked induration of the skin. Both control guinea-pigs and rabbits failed to react to the antigen.

An extensive trial, promising in the first place, was abandoned, owing to a fairly high percentage of false positive results.

Serological Tests (agglutination and complement fixation) were carried out in some of my cases-all with negative results*

The disease may be confused with arthropathic psoriasis, acute rheumatism in adults, septicæmia, Stevens-Johnson syndrome, Behcet's syndrome, ninth-day erythema of Milian, toxic manifestations of sulphonamides, serum sickness, secondary syphilis, and arthritis in association with certain fevers (for example, typhoid fever).

\section{Differential Diagnosis}

Arthropathic Psoriasis.-Many cases of arthropathic psoriasis have been described, wrongly I think, as Reiter's disease. The joint condition is one of rheumatoid arthritis, noted only in eight of my venereal series (it was considered to have supervened after destruction by acute inflammation), and on eight occasions in the dysenteric series of Gounelle and his collaborators. Difficulties in diagnosis commonly arise from the fact that the skin eruption sometimes consists of rupia-like lesions indistinguishable both clinically and histologically from the soft parakeratotic patches of keratodermia blennorrhagica ; indeed it is possible that both diseases may be caused by the same infective agent. However, in some of the cases described in the literature, as in the first of Löhe and Rosenfeld's series, the lesions developed subsequently into those of psoriasis vulgaris. The syndrome in a large majority of the cases of arthropathic psoriasis consists of rheumatoid arthritis and skin lesions only, and is very rarely associated with urethritis or conjunctivitis, indeed I have never seen a case with inflammation of eyes or urethra.

I recently saw -with Muende a man aged 45 with a two-years history of two or three very small lesions of psoriasis vulgaris situated on the elbows. It is interesting to note that two months after an attack of urethritis of venereal origin which was resistant to sulphonamide and penicillin therapy, the eruption became generalized. It was then characterized by three types of lesions : psoriasis vulgaris, psoriasis rupioides, and keratotic nodules (chiefly on the soles of the feet), which were indistinguishable from those of keratodermia blennorrhagica : urethral washings were positive for " $L$ " organisms.

Acute rheumatism in young adults may render

- For serological methods see Harkness and Henderson-Begg (1948). 
diagnosis extremely difficult. This is due to its pyrexial onset, to arthritis which is polyarthritic and migratory but never suppurative, and to the cutaneous manifestations. Several cases admitted under my care with a diagnosis of Reiter's disease have reacted favourably to salicylates and I have also had four cases of the disease, two in which the syndrome was complete, transferred to me after several months treatment in medical wards for acute rheumatism.

Septicamia.-Cases with the syndrome triad have been described in association with staphylococcal septicæmia and chronic meningococcal septicæmia : one of them (Biland, 1905) is wrongly reported in the literature as a case of Reiter's disease. The primary lesion was an osteomyelitis of an acromion process with secondary foci of bursitis, urethritis, epididymitis and subcutaneous abscesses : Staphylococcus aureus was isolated from all foci of infection. Junghanns (1918) also reported the case of a boy aged 16 with the syndrome triad which was regarded by him as a case of staphylococcal septicæmia. There was a previous history of boils fourteen days before the onset of the illness, but organisms were not demonstrated in any of the lesions: the case, in my opinion, was one of Reiter's disease.

The clinical syndrome of chronic meningococcal septicæmia which consists chiefly of muscle and joint pains, joint effusions, and recurrent skin eruptions usually of the erythema nodosum type, associated with relapsing or intermittent fever, may also be mistaken for Reiter's disease

Stevens-Johnson Syndrome, with its febrile onset, urethritis, balanitis, ocular lesions and skin eruption, may be associated with arthritis as in the cases described by Lever (1944). It may then be difficult to distinguish from Reiter's disease.

Behcet's Syndrome, which consists of severe recurring eye lesions, aphthous ulcers on oral and genital mucous membranes, and skin eruptions, may also be associated with urethritis and acute arthritis as it was in the cases reported by Schmidt (1940) and Cavara (1940).

Milian's Ninth-day Erythema, with its pyrexial onset, suffused conjunctivæ, scarlatiniform (sometimes papular) eruption, and swollen and painful joints may simulate Reiter's syndrome, and the differential diagnosis is even more difficult when it develops during treatment of primary abacterial urethritis (Harkness, 1948).

Toxic Manifestations of Sulphonamides.-As sulphonamide therapy is prescribed frequently in non-gonococcal urethritis it is as well to remember that toxic reactions, similar to those of ninth-day erythema, sometimes appear seven or more days after the commencement of treatment in those not previously sensitized to the drug.

Secondary Syphilis is rarely a source of error. Recently, however, a çase was admitted under my care with a diagnosis of Reiter's disease, in which a non-gonococcal urethritis due to meatal chancre was associated with suffused conjunctivæ, swelling of both knee joints, and a generalized psoriasiform syphilide.

Typhoid fever may be complicated by urethritis, conjunctivitis, and arthritis, and cases have been reported in which a diagnosis of Reiter's disease has been made.

Serum Sickness following administration of serum during an attack of dysentery is stated by MansonBahr to clear up spontaneously after a few days, but the delay in its appearance and the fact that it may be associated with fever, rash, and arthritis must sometimes render diagnosis extremely difficult.

\section{Aetiology}

Reiter isolated a spirochæte in the blood of his case and, in view of this, called the disease "spirochætosis arthritica," but in this respect all subsequent workers have failed. Macfie in 1917 reported the case of a native of the Gold Coast with a hæmorrhagic urethral discharge containing large numbers of actively motile spirochætes associated with arthralgic pains and severe iritis in both eyes. The condition, which reacted favourably to galyl and mercury, is wrongly referred to in the literature as a case of Reiter's disease.

Various types of organisms, including staphylococci, diphtheroid bacilli, streptococci, $B$. coli, and pneumococci, have been isolated in the urethral discharge by various workers, due no doubt to inadequate cleansing of the meatus before the taking of specimens. Stühmer (1921) found Grampositive bacilli in the four cases he described in 1916, but did not consider them to be responsible for the disease. No organisms are seen in smears, and cultures on ordinary media are sterile in a large majority of the cases when thorough cleansing of the meatus has preceded the taking of specimens : it is always so in my experience, provided no local treatment has been administered.

In my opinion there is no doubt that the venereal syndrome is contracted usually by normal sexual intercourse and occasionally by sodomy, and that the primary focus of infection (an abacterial urethritis) occurs in the urethra (Harkness, 1945). Recurrences of the disease invariably follow sexual intercourse, but it is admitted that in some cases the infective agent may have remained latent during the intervening period and re-activation of infection. may 
have been caused by an additional factor, for example, trauma, as has been shown by Burnet (1945) to be the case in recurrences of herpes simplex. Both the venereal and dysenteric syndromes are, in my opinion, due either to a virus or pleuropneumonia-like organisms.

The portal of entry of the infective agent in the dysenteric syndrome is presumed to be the diseased mucous membrane of the large intestine. The various dysenteric organisms do not cause the disease but it is possible that they are contaminated by the infective agent. On the other hand, the infective agent may be normally present in the large intestine and the advent of ulceration in dysentery enables it to reach the blood stream and set up complications in remote parts of the body. In possible support of this theory is the fact that freeliving strains of pleuropneumonia-like organisms have been isolated in sewage (Laidlaw and Elford, 1936) and manure (Seiffert, 1937), but it is admitted that the former workers, and also Beveridge (1943), failed to detect them in normal human fæces. On two occasions, once by Henderson-Begg (Harkness and Henderson-Begg, 1948) and once by Bushby (1947), pure cultures were obtained from anal swabs of two contacts of my cases of Waelsch urethritis in which the disease had been contracted by sodomy. I have recently isolated organisms in an anal swab taken from a normal individual, and also in a swab from the pelvo-rectal junction taken during sigmoidoscopy from a man aged 75 with fæcal impaction.

Smith (1942) and Dienes and Smith (1942) were the first to isolate " $L$ " organisms in the urethral discharge from cases of uncomplicated abacterial urethritis and Reiter's disease, and in 1948 these organisms were isolated in the synovial fluid of two cases of Reiter's disease by Dienes and his collaborators, and of one by Warthin. So far I have been unsuccessful in isolating " $L$ " organisms in the synovial fluid from five patients, and from the skin lesions of four.

In my address to the Medical Society for the study of Venereal Diseases in May, 1944, I recorded the finding of inclusion bodies, possibly a virus, in the scrapings from the urethra, conjunctiva, and skin lesions. At the time of these investigations the previous work concerning human strains of pleuropneumonia-like organisms in the urogenital tract was not known, but as the elementary bodies were accompanied often by rings, suggesting that the rings were developing from the granules, it was considered that the bodies were possibly a phase in the life cycle of " $L$ " organisms. If the " $L$ " organisms were saprophytes then it is not unlikely that both " $\mathrm{L}$ " organisms and virus were seen together.
Harkness and Henderson-Begg (1948) isolated " $L$ " organisms in twenty-one (38 per cent.) of fifty-seven cases of subacute abacterial or Waelsch urethritis, in five (50 per cent.) of ten cases of acute abacterial urethritis, and in seven (17 per cent.) of forty-one cases of Reiter's disease : only seven of the latter presented the complete syndrome, and two (29 per cent.) gave positive cultures. A much higher percentage of positive cultures in Reiter's disease was obtained when urethral washings were carried out during the acute phase of the disease, and many failures occurred in cases in which admission to hospital was delayed.

Giemsa-stained smears were examined from all my cases, and in many of those in which cultures were positive for " $L$ " organisms epithelial cells were seen with the cytoplasm packed with large numbers of small bluish- or purple-staining bodies which showed marked pleomorphism: spherules, ovoids, rickettsia-like forms, and elementary-like bodies were observed, with a high proportion of ring-like forms showing wide morphological variation : these bodies were also noted lying free, both dispersed and in small clusters.

Though absent during intervening periods, " $\mathrm{L}$ " organisms have been isolated by Bushby in urethral washings of several of my patients during recurrent attacks of the disease. In four such cases in which it was possible to examine contacts cervical swabs were also positive. In this respect it is interesting to note that in one of the cases reported by Dienes and his collaborators (1948), "L" organisms isolated in the prostatic secretions during three recurrent attacks were absent during the intervening periods.

Florman and Goldstein (1948) are the only workers who have attempted to incriminate " $L$ " organisms in the dysenteric syndrome. They failed to isolate these organisms or a virus in the urethral discharge, conjunctival secretion, and synovial fluid of their case.

There are many other workers who believe in a virus ætiology but so far the evidence brought forward has been scanty.

We have failed to cultivate a virus on the chorioallantoic membrane of chick embryos, in mouse brain inoculation, and in tissue culture, and so far no other workers have been successful. In this respect it must be remembered that attempts to cultivate the virus of inclusion conjunctivitis from the eyes of babies have also been unsuccessful.

Dodd and others (1938) showed that aphthous stomatitis in infants and young children is in most cases due to the virus of herpes simplex and a virus has recently been shown by Buddingh (1946) to be responsible for a similar disease associated with diarrhœa in children. Strains of the virus are 
maintained by serial passage from cornea to cornea of rabbits, but, unlike primary herpetic stomatitis, no inclusions have been found. In the discussion following Buddingh's paper on this subject Sabin stated that these inclusions would probably be demonstrated in serial sections. On this occasion Dodd also reported that she had obtained positive corneal inoculations in rabbits with vaginal swabs taken from the mothers of the children suffering from the disease. Buddingh had observed similar results with the urethral discharge and oral and conjunctival secretions of a typical case of Reiter's disease.

Dunham and his collaborators (1947) isolated a filterable agent pathogenic for mice from the urethral and conjunctival discharge of their case of Reiter's disease in a man aged 23. Suspensions of the urethral discharge and conjunctival secretion (in heart infusion broth and 10 per cent. beef serum) were each inoculated into the allantoic fluid of twelve-day embryonated eggs, twelve eggs being used for each suspension. After being sealed with paraffin the eggs were incubated for forty-eight hours and then chilled for two hours; when the allantoic fluid from each series was pooled and filtered through a Seitz E.K. filter. Twenty mice were inoculated intraperitoneally with $0.1 \mathrm{ml}$. of one of four different saline dilutions with the filtrate derived from the urethra and a like number with that from the eye : twenty mice also served as controls. Sixty per cent. of the mice injected with material from the eye and urethra developed conjunctivitis : the eyes of the controls were all normal.

It should be mentioned that certain workers, including Creecy and Beazlie (1948) stress the importance of focal infection. In the two cases described by Creecy and Beazlie an acute exacerbation of signs and symptoms followed the removal of foci of infection, in one the extraction of a tooth with an apical abscess and in the other tonsillectomy for septic tonsils. In my opinion the occurrence of such exacerbations is due entirely to the protein shock effect of the bacteriæmia, and it has been noted in many of my cases following the extraction of teeth during the course of the disease. It does not signify that the causal agent is present in these foci of infection.

Other workers maintain that the disease is an allergic one. Thiers and Joly (1948) collected the urethral discharge in the first $5 \mathrm{ml}$. of urine passed, and injected $0.5 \mathrm{ml}$. of this solution intradermally. No reactions occurred at the injection site, but a severe systemic reaction with high fever and an acute exacerbation of the arthritis followed, and in view of this the author regarded the disease as an allergic process.
Although the atiology of the disease is still uncertain, the fact that a high percentage of positive cultures for " $L$ " organisms is obtained in the types of non-gonococcal urethritis associated with the disease, their absence from normal cases, their disappearance with successful treatment, their recurrence in re-infections, their presence in a high percentage of contacts, and the fact that they have been isolated in the synovial fluid, all tend to support the conclusion that organisms of this group may be responsible for the venereal syndrome. It is admitted that serological tests do not bear this out, but negative results cannot be regarded as strong evidence against the incrimination of " $L$ " organisms, as little is known of their antibody response in the human being. It may be that antibodies are present in low concentrations, and for such short periods that they are not demonstrable by the relatively crude methods ${ }^{-}$at present available. However, I do maintain (and there are experts in virus diseases who agree with me) that some of the bodies I have demonstrated in scrapings from urethra, conjunctiva, and skin lesions in Reiter's disease are a virus and not " $L$ " organisms. The inclusion bodies seen in these lesions are morphologically indistinguishable from each other, a fact that points very strongly to a common virus causation. It is a comparatively easy matter to demonstrate inclusion bodies in inclusion conjunctivitis in babies, and the difficulty in demonstrating them in scrapings from urethral mucosa is almost certainly due to the fact that the extreme sensitivity of this structure prevents the taking of adequate specimens.

\section{Treatment}

The primary focus of infection in the venereal syndrome being the urethra, perhaps it will not be out of place if I stress here the importance of adequate treatment of this focus in the prevention of blood-borne complications.

It was my practice in the pre-sulphonamide era to treat all cases of primary urethritis, gonococcal and non-gonococcal, with twice-daily urethrovesical irrigations of potassium permanganate or oxycyanide of mercury, and none of these patients to my knowledge subsequently developed bloodborne complications. Nowadays, the majority of venereologists, including myself, omit local treatment for gonorrhœa. During the last year I have observed fifteen cases in which penicillin has eliminated the gonococcal element from the urethral discharge, but the persistence of a non-gonococcal discharge has been followed by metastatic complications. I therefore consider that all cases of primary non-gonococcal and residual post-gono- 
coccal urethritis should be treated with urethrovesical irrigations and that, when these are efficiently carried out, blood-borne complications will not arise.

Powell and others (1946) showed that streptomycin protected rats and mice from developing arthritis after injection in the pad with animal strains of " $L$ " organisms, and Bushby (1947) found that " $L$ " organisms of human origin were sensitive to low concentrations of the antibiotic. Therefore, if pleuropneumonia-like organisms are proved to be responsible for the disease, streptomycin should be the drug of choice. I have treated two cases with streptomycin. Both received $10 \mathrm{~g}$. only $(0.25 \mathrm{~g}$. six-hourly for ten days). In the first case an excellent result was obtained, but no beneficial effects were noted until a few days after the completion of treatment. The other case, in which the syndrome was complete, the same dosage was ineffective. Another case (not included in this series) received 20 g. (0.5 g. six-hourly) and developed typical lesions of keratodermia blennorrhagica during treatment.

Warthin (1948) states that the effects of streptomycin in the treatment of chronic prostatitis due to infection with " $L$ " organisms were so striking that he treated four cases of Reiter's disease, three for seven days with a total daily dose of $4 \mathrm{~g}$., and one with $2.5 \mathrm{~g}$. daily for ten days. Warthin states that the results were " not conclusive but still sufficiently encouraging to warrant further use of this form of therapy." Improvement in the first case occurred during the first week following streptomycin (as in my first case), but in the third and fourth cases the beneficial effects of treatment were, in my opinion, dramatic : the discharge ceased, the urine cleared, pain in the joints ceased, and fluid in the knees was absorbed during treatment.

On the other hand Dienes and his collaborators (1948), in the treatment of six cases, noted improvement during and immediately after streptomycin (4 g. daily for thirteen days), and " $L$ " organisms disappeared from the secretions but inflammation in joints persisted for considerable periods and, as already noted, the erythrocyte sedimentation rate did not fall. These workers state that the drug does not prevent recurrences of the disease. This has been my experience also, as.one of my two patients has since had a relapse after intercourse with his wife, who was still harbouring " $L$ " organisms.

Findlay and his collaborators (1940) showed that organic gold salts also protected rats and mice from developing arthritis after injection of " $L$ " organisms in the pad. Willcox and others (1947) found gold salts curative in two patients with Reiter's syndrome, but the results I have obtained in the treatment of eight cases with myochrysine have not been so striking. In one the result was equal to that obtained with fever therapy, but in the others fever therapy was necessary to effect a cure. Beneficial effects of gold therapy may be non-specific and may be due to the rise in temperature which commonly occurs for an hour or more after each injection ; and this may be overlooked with a four-hourly chart (Harkness, 1947).

The following is the treatment I have carried out during the last ten years, and, until streptomycin becomes available, I shall continue on the same lines.

Treatment of the primary focus of infection consists of twice-daily urethro-vesical irrigations with oxycyanide of mercury, 1 in 6,000 . Urethroscopy will reveal both the presence of urethral stricture and the persistence of infiltrations, and in such cases dilatations are necessary. Blood-borne complications commonly react favourably to nonspecific protein therapy, mild or severe. During the first week of the illness it is my usual practice to give three intramuscular injections of aolan, each of $10 \mathrm{ml}$., and if results are satisfactory the injections are repeated during the following week. Unsatisfactory results demand more severe protein shock therapy with sharp rise in fever. I prefer fever induced either by the intravenous injection of triple typhoid vaccine (T:A.B.) or pyrifer (Bacillus coli vaccine). Five bouts of fever are usually given, and in relapsing cases it may be necessary to repeat the course : coupled dosage also may be called for.

Harman recently treated a case, in which the syndrome was complete with chloromycetin $(2 \mathrm{~g}$. three times for one day followed by $\mathbf{I}$ g. three times daily for seven days). During treatment further joints became involved; the temperature, which was already high, rose higher, and a fresh crop of skin lesions of keratodermia blennorrhagica appeared. I know of no cases treated with aureomycin.

Assessment of the effects of treatment is difficult (a few cases improve with rest alone) unless dramatic results are obtained. Penicillin and the sulphonamides are, in my hands, always ineffective. Large doses of salicylates ( 30 gr. four-hourly) are sometimes followed by excellent results, but this may be due to mistaken diagnosis.

Local treatment of the affected joints consists in rest and partial immobilization with sand-bags for the lower and a sling for the upper limbs. On no account should immobilization be by splints or plaster-of-paris, as such measures will eventually cause adhesions and ankylosis. Radiant heat baths for twenty minutes, twice daily, give considerable relief when the pain is severe, and aid resolution. As soon as the acuteness subsides, massage of the 
muscles above and below the joints, combined with passive and later active movements, helps considerably in restoring function.

Local treatment for the eyes consists of guttæ hyoscine, 0.5 per cent. twice daily, and sulphacetamide, 30 per cent. four-hourly : also boracic eye baths.

Local treatment for skin lesions is rarely necessary.

\section{REFERENCES}

Annotation (1946). Brit. med. J., 2, 865.

Bauer, W., and Engleman, E. P. (1942). Trans. Ass. Amer. Phys., 57, 307.

Beck, F. (1937). Med. Klin., 33, 1162.

Beiglböck, W. (1943). Dtsch. med. Wschr., 69, 803. (See also abstract by Manșon-Bahr, P. H. (1944). Bull. War Med., 4, 653.)

Beveridge, W. I. B. (1943). Med. J. Aust., 2, 479.

Biland, J. (1905). Corr Bl. Schweiz. Arzte, 35, 377.

Bonnin, N. J., and Kay, H. B. (1943). Dysenteric arthritis; case reports and comments. Med. J. Aust., 2, 380.

Brodie, B. (1818). PathologicaT and Surgical Observations on Diseases of the Joints. p. 55.

Buddingh, G. J. (1946). Virus stomatitis and virus diarrhœa of infants and young children. Sth. med. J., 39, 382.

Burnet, F. M. (1945). Virus as Organism, p. 47. Harvard Univ. Press, Cambridge, Mass.

Bushby, S. R. M. (1947). Personal communication.

Cavara, V. (1940). Nuove osservazione ed ulteriori ricerche sulla ipopionirite recidivante associata ad alterazione delle mucose e della cute. Boll. ocul., 29, 789 .

Cimbal, O. (1942). Das Reitersche Syndrom als Nachkrankheit der Ruhr. (Beobachtungen an 114 Kranken unter-besonderer Berücksichtigung der Augenerscheinungen.) v. Graefes Arch. Ophth., 145, 142.

Colby, F. H. (1944). Renal complications of Reiter's disease. J. Urol., 52, 415.

Coutts, W. E. (1947). Reiter's disease. Brit. med. J., $1,310$.

Creecy, A. A., and Beazlie, F. S. (1948). Reiter's syndrome and focal infection. J. Urol., 59, 234.

Dienes, L., and Smith, W. E. (1942). Relationship of pleuropneumonia-like (L) organisms to infections of the human genital tract. Proc. Soc. exp. Biol., N.Y., 50, 99.

-, Ropes, M. W., Smith, W. E., Madoff, S., and Bauer, W. (1948). The role of pleuropneumonialike organisms in genitourinary and joint diseases. New Engl. J. Med., 238, 509 ; 563.

Dodd, K., Johnston, L. M., and Buddingh, G. J. (1938). Herpetic stomatitis. J. Pediat., 12, 95 .

Dunham, J., Rock, J., and Belt, E. (1947). The isolation of a filterable agent pathogenic for mice from a case of Reiter's disease. J. Urol., 58, 212.

Feiring, W. (1946). Reiter's disease with prolonged auriculoventricular conduction. Ann. int. Med., 25, 498.

Fiessinger, N., and Leroy, E. (1916). Contribution a l'étude d'une épidémie de dysentérie dans la Somme (juillet-octobre 1916). Bull. Soc. méd. Hôp. Paris, 40, 2030.

Findlay, G. M., Mackenzie, R. D., and MacCallum, F. O. (1940). Chemotherapeutic experiments on pleuropneumonia-like organisms in rodents. Brit. $J$. exp. Path., 21, 13.
Florman, A. L., and Goldstein, H. M. (1948). Arthritis, conjunctivitis and urethritis (so-called Reiter's syndrome) in a four-year-old boy. J. Pediat., 33, 172.

Frühwald, R. (1928). So-called spirochætosis arthritica (Reiter, 1916). Urol. cutan. Rev., 32, 7.

Gabrielle, H., Hugenot, G., and Duval, M. (1938). Lyon Med., 162, 299.

Gateley, J. R. (1945). Case of keratodermia blennorrhagicum (gonorrheal dermatitis). U.S. Nav. med. Bull., 45, 1159.

Gounelle, H., Bohn, A., Koskas, C., and Marche, J. (1940). Sur la maladie rhumatismale, post-dysenterique (formes febriles prolongees, syndrome sanguin et humoral, alterations osseuses, essais therapeutiques). Bull. Soc. méd. Hôp. Paris, 56, 821.

Harkness, A. H. (1945). Cutaneous manifestations of gonorrhœa. Brit. J. vener. Dis., 21, 93. (1947). Reiter's disease. Brit. med. J., 1, 72. (1947). Reiter's syndrome. Ibid., 1, 611.

(1948), Discussion on non-bacterial infections of the urinary tract. Brit. J. vener. Dis., 24, 121.

- and Henderson-Begg, A. (1948). The significance of pleuropneumonia-like or ' $\mathrm{L}$ ' organisms in nongonococcal urethritis, Reiter's disease, and abacterial pyuria. Ibid., 24, 50 .

Harman, J. B. (1949). Personal communication.

Junghanns, O. (1918). Ein weiterer Fall von Urethritis non gonorrhoica und septischer Allgemeinerkrankung. Dtsch. med. Wschr., 44, 1304.

Kardung (1941). Ein unter dem Bilde der Reiterschen Erkrankung verlaufender Fall von Urethritis, Arthritis und Conjunctivitis. Med. Welt, 15, 403.

Kokko, U. P. (1945). Uber Flexner-Bazillen und Flexner-Dysenterie. Acta med. scand., Suppl. 167.

Kraïter, J. (1871). Ueber einige Nachkrankheiten der Ruhr. Ein Beitrag zur Aetiologie der acuten und chronischen Gelenkentzündungen und der Blenorrhœn der Conjunctiva. 2. Aufl. Cassel.

Kristjansen, A. (1929). Fall zur Diagnose. Zbl. Haut-u. Geschl Kr., 31, 165.

-(1930). Ikke gonorrhoisk Uretritis med Konjunktivitis og Artroitis. · Ugeskr. Laeg., 92, 276.

Kruspe (1941). Zur Atiologie der Reiterschen Erkrankung. Derm. Wschr., 112, 457.

Kuske, H. (1939). Uber die Hauterscheinungen bei Morbus Reiter. Arch. Derm. Syph. Wien, 179, 58.

Laidlaw, P. P., and Elford, W. J. (1936). A new group of filterable organisms. Proc. roy. Soc., B 120, 292.

Launois, P. E. (1899). Artropathies récidivantes ; amyotrophie generalisée, troubles trophiques multiples (cornes cutanées, chute d'un ongle) d'origine blennorrhagique. Bull. Soc. méd. Hôp. Paris, 3 Ser., 16, 736.

Lever, W. F. (1944). Severe erythema multiforme. Arch. Derm. Syph. Chicago, 49, 47.

- and Crawford, G. M. (1944). Keratosis blennorrhagica without gonorrhœa (Reiter's disease). Ibid., $49,389$.

Löhe, H., and Rosenfeld, H. (1929). Klinische und physiologisch-chemisch Untersuchungen uber die Hyperkeratosenbildung bei Gonorrhœ und bei Psoriasis pustulosa arthropathica. Derm. Z., 55, 355.

Lojander, W. (1927). Uber Keratodermien im Anschluss an Gelenkaffektionen gonorrhoischen und nichtgonorrhoischen Ursprungs. Acta derm.-venereol. Stockh., 8, 227.

Macfie, J. W. S. (1917). Urethral spirochætosis. Parasitology, 9, 274.

Manson-Bahr, P. H. (1920). The common complications of bacillary dysentery in military practice. Brit. med. J., 1, 791 . 
Manson-Bahr, P. H. (1943). The Dysenteric Disorders, p. 19. London.

(1945). Manson's Tropical Diseases, pp. 475, 484. 12 th ed. London.

Markwald, B. (1904). Ueber seltene Complicationen der Ruhr. Z. klin. Med., 53, 321.

Miller, C. D., and McIntyre, D. W. (1945). A syndrome termed Reiter's disease (urethritis, conjunctivitis and arthritis). Ann. int. Med., 23, 673.

Muende, I. (1949). Personal communication.

Patzel, H. (1928). Uber Polyarthritis nach unspezifischer Urethritis. Med. Klin., 24, 134.

Paronen, I. (1948). Reiter's disease : a study of 344 cases observed in Finland. Acta med. scand., Suppl. 212.

Postma, C. (1937). A case of Reiter's disease. Acta derm.-venereol. Stockh., 18, 69.1.

Powell, H. M., Jamieson, W. A., and Rice, R. M. (1946). Effectiveness of streptomycin in arthritis of rats. Proc. Soc. exp. Biol., N.Y., 62, 8.

Reiter, H. (1916)./ Ueber eine bisher unerkannte Spirochateninfektion (Spirochætosis arthritica). Dtsch. med. Wschr., 42, 1535

Ruge, H. (1928). Bemerkungen zu der Arbeit von Frühwald : "Spirochætosis arthritica." Derm. Z., 54, 98.

Schmidt, R. (1940). Zum Krankheitsbild der rezidivierenden Hypopyon-Uveitis. v. Graefes Arch. Ophth., 142, 185.

Seiffert, G. (1937). Ueber das Vorkommen filtrabler Mikroorganismen in der Natur und ihre Zuchtbarkeit. Zbl. Bakt., Abt. I., 139, 337.

Shiga, K. Quoted by Markwald, B. (1904).

Singer, G. (1915). Erfahrungen in der letzten Dysenterieepidemie. Munch. med. Wschr., 62, 183.
Singer, G. (1915). Ueber dysenterische Rheumatoide Wien. med. Wschr., 65, 317.

Smith, W. E. (1942). Isolation of pleuropneumonialike (L) organisms from man. J. Bact., 43, 83.

Smyly, H. J. Quoted by Manson-Bahr, P. H. (1943).

Sommer, A. (1918). Drei wahrscheinlich als "Spirochætosis arthritica" (Reiter) anzusprechende Krankheitsfälle. Dtsch. med. Wschr., 44, 403.

Storm-Mathisen, A. (1946). Cutaneous tests for Reiter's disease; preliminary report. Acta derm.-venereol. Stockh., 26, 547.

Stühmer, A. (1921). Ueber die sogenannte "Spirochætosis Arthritica" (Reiter). Munch. med. Wschr., 68, 769.

Thiers, H., and Joly, L. (1948). Étude de l'allergie au cours du syndrome de Reiter : existence d'un allergene dans le pus uréthrale amicrobien. Rev. Rheum. Mal. Osteo-Arthr., 15, 11.

Waelsch, L. (1916). Uber chronische, nicht gonorrhoische Urethritis. Arch. Derm. Syph. Wien, 123, 1089.

Warthin, T. A. (1948). Reiter's syndrome : a report of four patients treated with streptomycin. Amer. J. Med., 4, 827.

Wepler, W. (1942). Zur Morphologie und Pathogenese der postdysenterischen Polyarthritis. Beitr. path. Anat., 106, 289.

Wiedmann (1934). Reitersche Erkrankung. Wien. klin. Wschr., 47, 1245.

Willcox, R. R., Findlay, G. M., and Henderson-Begg, A. (1947). Treatment of Reiter's syndrome by gold salts. Brit. med. J., 1, 483.

Zia, S. H., and Smyly, H. J. (1931). Arthritis in association with bacillary dysentery. Nat. med. J. China, 17, 307.

\section{DISCUSSION ON REITER'S DISEASE}

In answer to a question from the President, Dr. Harkness said that he used Giemsa's stain when demonstrating inclusion bodies.

Dr. JoNes said that at Endell Street Clinic cultures for " $L$ " organisms were positive in 131 cases of urethritis in the male. In a series of sixty-three cases of primary non-gonococcal urethritis twenty-six $(41 \cdot 2$ per cent.) were found to be positive : this percentage would have been higher but for the inclusion of several cases of bacterial (non-gonococcal) urethritis. Six contacts of this group attended, and in all of them vaginal and cervical swabs yielded positive cultures.

In a series of fifty-seven cases of gonorrhœa, nineteen (33 per cent.) were found to be positive. Seven (63.6 per cent.) of eleven cases of residual post-gonococcal urethritis yielded positive cultures : the only contact examined was also positive.

Eleven patients were treated with streptomycin, the dosage varying between 0.5 and $1.5 \mathrm{~g}$. daily for ten days. Cultures showed that five $(\mathbf{4 5 . 4}$ per cent.) remained positive on completion of treatment. Twentyfour other patients received only urethro-vesical irrigations for seven to fourteen days. Cultures after treatment showed that twenty (83.3 per cent.) of these had become negative.
Dr. Chesney stated that during recent months, in addition to the routine investigations of female patients at the Endell Street Clinic, cultural examinations for " $L$ " organisms in vaginal and cervical secretions have also been carried out. It is difficult at the present moment to describe exactly the clinical picture in the female or to state the significance and relationship of pleuropneumonia-like organisms to other infections of the female genital tract. So far Bushby (who has carried out the cultures) has been unable to differentiate between pathogenic and non-pathogenic strains. On the other hand Edwards has succeeded in doing so in bovine strains.

Cultural examinations for " $L$ " organisms were positive in fifty-three of the seventy-six cases investigated. Positive cultures were recorded in :

15 of 28 cases of non-gonococcal cervicitis ;

14 of 19 cases of non-gonococcal cervicitis and trichomonas vaginitis ;

5 of 7 cases of gonococcal cervicitis ;

5 of 7 cases of gonococcal cervicitis and trichomonas vaginitis ;

1 of 2 cases of syphilis and non-gonococcal cervicitis and trichomonas vaginitis ;

1 of 1 case of syphilis and non-gonococcal cervicitis ;

5 of 5 cases of syphilis and gonococcal cervicitis ; 